\title{
Air Flows: Breath, Voice, and Authenticity in Three Recordings
}

\author{
Gregory Weinstein \\ Davidson College \\ grweinstein@davidson.edu
}

\begin{abstract}
Miley Cyrus inhales audibly before launching into the final chorus of "Wrecking Ball". Cellist David Soyer grunts as he tears through the Beethoven's Grosse Fuge. Saxophonist Colin Stetson's loud circle breathing on "Hunted" pushes the limits of the physically possible. These recordings all contain traces of the musicking bodies that they purport to represent. This article will treat the breath not as excess, but rather as part of the core musical content of recordings. The breath and the grunt are sounds are often considered excess - not properly musical - yet they are crucial to the affects of these tracks. They validate the recorded performance by pointing to the lingering aura of the musicians who produced them, even while they reveal the ways in which the recording studio can reconfigure, extend, and naturalize these mediatized musicking bodies. On recordings breath becomes a tool through which musicians and recordists can construct the embodied authenticity of the recording. This article argues that the sound of breath is essential to the perception of embodied authenticity on recordings - evidenced by the development of genre-specific conventions for treating breath and constructing the body on recordings.
\end{abstract}

KEYWORDS: recording, breath, embodiment.

I'm still breathing,

I'm alive.

—Sia, "Alive" (2015) 


\section{Introduction: from voice to breath}

Scholars of music are very used to thinking about the voice as an embodied musical sound (for example, see Brooks 2000; Feldman 2015; Rahaim 2008). Singers produce sound from within the body itself. That musical sound emanates from the chest, throat, and mouth, and is projected into a physical space where it resounds and is perhaps perceived by listeners. Once the voice departs from the singer's body it enters a network of complex social and sonic relationships with other sounds, other forms of "musicking" (Small 1998), ${ }^{1}$ and other types of mediation that characterize contemporary musical cultures. The perception of the singer's voice through these networks and media constitutes an embodied act. Such embodied acts are called "ubiquitous listening" by Anahid Kassabian in order to account for the vast array of listening modes and contexts that comprise one's affective sonic world (Kassabian 2013). Listening of this sort makes the singer's body a central figure for analysis, via the voice, and in this regard, singing is conceived as the form of musicking that is innately human. As Richard Middleton has observed, the voice is "commonly understood ... as the profoundest mark of the human" (1990: 262).

The direct connection of voice to body is suggested by Carolyn Abbate, who remarks that "singers, unlike instrumentalists, are not mutely clutching dead objects of wood or metal that 'make music' ... And singers are not media. They seem to "speak for themselves" (Abbate 1999: 483). The word "seem" is critical to Abbate's meaning. Listeners perceive the singing voice to be the authentic voice of the person who is singing, yet the voice of the singer is simultaneously strange and familiar - uncanny, perhaps - because of listeners' knowledge of their own bodies and their own voices. The singing voice is not only communicative; it is also the result of production techniques that are mysterious to or hidden from the listener. In psychoanalytical terms, the voice is prelinguistic, precultural, and pure. It is "the link which ties the signifier [the language] to the body", according to Mladen Dolar. "It indicates that the signifier, however purely logical and differential, must have a point of origin and emission in the body. There must be a body to support it" (Dolar 2006: 59).

The body is figured as a precondition for the voice and all of its expressive possibilities, and the voice is presumed to emanate from a coherent and vocally capable body. Coherence - the perception of a voice emanating naturally from a body - is an important assumption for scholars who have positioned the voice as uniquely human. According to Simon Frith,

The voice as a direct expression of the body ... is as important for the way we listen as for the way we interpret what we hear: we can sing along, reconstruct in fantasy our own sung versions of songs, in ways we can't even fantasize instrumental technique ... because with singing, we feel we know what to do. We have bodies, too, throats and stomachs and lungs. (Frith 1996: 192, emphasis original)

Yet in arguing for the embodied perception of the voice, scholars like Frith do not account for the particular physiological processes that produce the voice - one of which is breath. Scholars seem much less comfortable thinking about breath as a 
sonic signifier in music; few do more than nod to its presence. ${ }^{2}$ Roland Barthes acknowledges breath, but he does so only to lament that "the whole of musical pedagogy teaches not the culture of the 'grain' of the voice" - which might convey something of the performer, and therefore constitutes the proper object of musical study - "but the emotive modes of its delivery - the myth of respiration" (Barthes 1977: 183, emphasis added). For Barthes, the lung is "a stupid organ". Rather, "it is in the throat, place where the phonic metal hardens and is segmented, in the mask that significance explodes" (ibid, emphasis original). Steve Savage suggests that it is not "the actual breath that [Barthes is] referring to but rather the reliance on breath for expression" (Savage 2011: 55). Savage's observation aligns with the ideas of renowned vocal teacher and scholar Richard Miller, who argued that singers should strive for "immediate and silent renewal of the breath" (Miller 1997: 37, emphasis in original). Miller, like the vocal pedagogues criticized by Barthes, relegates breath to a hidden role in musical expression. However, following Savage, I see breath as more than a necessary but inexpressive complement to voice; rather I will show how the sonic presence of breath on a recording can contribute to the perception of bodily coherence.

This article aims to take a small step towards considering breath as a sonic element of embodied music production and perception. Its purpose is to move beyond the idea that breath is merely an index of the voice and to propose that it is perhaps better considered an expressive device in its own right. Just as Barthes suggests that a voice has a "grain", we should follow film scholar Davina Quinlivan's proposal that breath has "grain", too (Quinlivan 2012: 137). As Serge Lacasse (2010) has recognized in his discussion of "paralinguistic features" of the recorded voice, the sonic properties of breath are tremendously affective, conveying effort, intensity, and even intimacy to listeners. Breath functions similarly to voice in that it is perceived in an embodied way by listeners, who understand the sound of breath with reference to their own bodily function.

However, breath, like voice, can be mediated and manipulated - subjected to all of the same musical and technological processes as voice. Within modern recording studios, a singer's voice and breath can be processed and spliced to contribute to a sonic persona and a continuous performance that may exist nowhere other than in the mediatized space of the studio. The recording studio problematizes the notion of voice as coherent and, therefore, the correlating idea that a coherent voice necessarily corresponds with a coherent "musicking body", a term developed by Matthew Rahaim with regard to Hindustani music to describe "a trained body in action, engaged mindfully in singing and/or playing an instrument" (Rahaim 2012: 2). Further, as I have already suggested about recorded musicians, Rahaim observes that the "musicking body" is at once continuous with and marked as distinct from the musician's quotidian body: "When a singer beings to sing ... it is as though ... some entirely different person has replaced the person who was there a moment before" (ibid).

The second and primary purpose of this article is to argue that the sound of breath on music recordings should be understood as a part of the expressive sonic apparatus of the recording medium. In this regard, I dispute a longstanding assumption of scholarship on music and recording - namely, that breath does not have any aesthetic meaning or value in its own right. Simon Zagorski-Thomas argues that 
In any "real life" performance situation there will be both desirable sound, the noise the musicians make, and undesirable sound, any unintended noise that nevertheless happens during the performance ... Close microphone placement can reduce some of the sounds but can also make others worse: the musicians turning the pages of their music, their chairs creaking, the rustle of their clothing as they move or the sound of their breathing. (Zagorski-Thomas 2014: 59, emphasis added)

Zagorski-Thomas elaborates that the presence of an "undesirable sound" such as breathing contributes to an "unwanted realism" (ibid) of a recording, and therefore, the removal of the sound of breath from recordings is done "to render the sound less human and more abstract" (Zagorski-Thomas 2014: 60). There are at least two terms that might refer to the removal of breath from a recording: "deessing ... which can be used to reduce the volume of sibilance or breath noises" (ibid); and "de-breathing", a term that recording engineers sometimes use to describe the painstaking process of cutting (manually or digitally) the sound of breathing from a recording. ${ }^{3}$ Savage describes a piece of software called DeBreath, which is used for the "manipulation or elimination of breaths" in the recording process (Savage 2011: 53).

At the same time, the complete removal of breath from a recording is not always desirable. For instance, in addition to the removal of breath, Savage details the painstaking process of deciding which breaths best fit in which positions in a recording (ibid). Guided by genre conventions in the recording studio, recordists must determine how much breath to leave in so that listeners will perceive the recording as "real". In an earlier meditation on the topic, Zagorski-Thomas observed one question that might be troubling to listeners of a recording: "How much room for breath needs to be left in a spliced performance before we perceive it as an activity that is impossible to generate, and therefore artificial?" (Zagorski-Thomas 2007: 197). Paradoxically, those "less human" recordings with fewer (and more tightly controlled) breath sounds may be perceived by listeners as more human than an untouched recording.

The trick of producing breath on a recording lies in the ability of the musicians and recordists (a general term to refer to producers and engineers) to mediate the desire for a relatively pure rendering of a musical work with the need for a recorded performance to be perceived as human. The precise nature of this balancing is dependent on a large number of factors, primarily revolving around the particular conventions of musical genres and forms. Rock recordings conventionally permit different sorts of interventions than do classical recordings. For example, and listeners' expectations about the "authenticity" of the recorded performance varies according to genre cultural context. ${ }^{4}$ This article does not assert any hard-and-fast rules for how breath should appear on recordings, however, its three case studies reveal the breadth of possibilities for breath in a recording context. These dramatically contrasting recordings highlight the points of contact and overlap between the musical practices and recording conventions of apparently distinct musical forms. For it may seem that the case of the Guarneri Quartet presents the most natural and unmediated representation of breath, insofar as the sound of breath in their recording is less of an artistic intention than a by-product of their other performance practices and habits. However, I will 
show that the authenticity of the Guarneri recording, as embodied by the sound of breath, has much in common with the far more deliberate breathing and recording techniques of saxophonist Colin Stetson and pop singer Miley Cyrus. Each of these recordings makes particular claims about the "liveness" - the mediatized, embodied authenticity (see: Auslander 2008) - of the recorded musical performance. By attending to the sound of breath, we can understand something of the processes and conventions through which the body is produced within the collective and collaborative acts of recording music.

\section{Track 1: Guarneri Quartet, Grosse Fuge}

The first recording I shall consider is the Guarneri Quartet's 1969 recording of Beethoven's Grosse Fuge (op. 133; RCA 1990). Originally composed as the finale to his String Quartet in B-flat (op. 130), the fugue was deemed too difficult and was severed at the recommendation of his publisher. It was subsequently published as a stand-alone work. The reasons why Beethoven separated the fugue from the rest of the quartet, replacing it with a comparatively trifling finale, has been much discussed by biographers: "some have attributed it to his preoccupation with [nephew] Karl [van Beethoven]'s suicide attempt; others to his desire for an additional 15-ducat payment; still others to his disdain for those who were unable to grasp his intention" (Solomon 1998: 421). This debate has spawned another, wherein performers must decide whether the fugue or its replacement is the appropriate one with which to close the B-flat quartet. ${ }^{5}$ We might suppose, following Tia DeNora's research on the discourse of "genius" (DeNora 1995), that severing the fugue was a tactical move on Beethoven's part and even if it was not, the end result has surely been to elevate the Grosse Fuge to the zenith of the Romantic string quartet repertoire - the most difficult of works that a quartet must tackle in order to be recognized as truly accomplished.

The Grosse Fuge was clearly regarded by the Guarneri Quartet as one of the repertoire's most challenging, described by violinist John Dalley as "Herculean" and by violist Michael Tree as akin to "scaling a mountain peak" (Blum 1986: 164). By referring to the fugue in plainly athletic terms, these musicians recognize the extreme physical demands placed on the quartet. This encompasses: the endurance to play a taxing work that generally lasts well over 15 minutes; the necessity of coordinating four distinct parts playing complexly interlocking themes and countermelodies; and the need to shape a musical trajectory over the full breadth of the work. The Grosse Fuge is a deeply physical work that makes plain the physical demands it places on the performers.

Thus, it is little surprise that even in the recording context, one might encounter sonic evidence of the physical strain of performing the Grosse Fuge. In the case of the Guarneri Quartet's recording, this evidence takes the form of the quartet members breathing and grunting at several key points in the work. For instance, in the fugue's coda, the rhythmic feel of the work slows from two beats to the bar to a single beat (mm. 611-36). At this point there are several audible breaths that mark the movement of the cello on the bass line. As the slow, suspended passage gives way to a series of short and heavily stressed chords, the breaths cease and are replaced by a series of audible grunts aligned with each chord (see FIGURE 1). 
While I cannot be positive that these breaths and grunts are produced by cellist David Soyer, this seems the most logical conclusion. This reading is evidenced by the breaths lining up with notes that Soyer articulates. Since his part moves at a slower rate than the rest of the quartet, it make sense that he would breathe to mark his changing notes. Moreover, the audible grunts are pitched on a low $\mathrm{F}$ (F1), two octaves below the cello's first loud pitch (and one octave beneath the viola); as the grunts seem to articulate the passage's bassline, I find it more likely that they are Soyer's voice than a musician playing one of the upper lines.

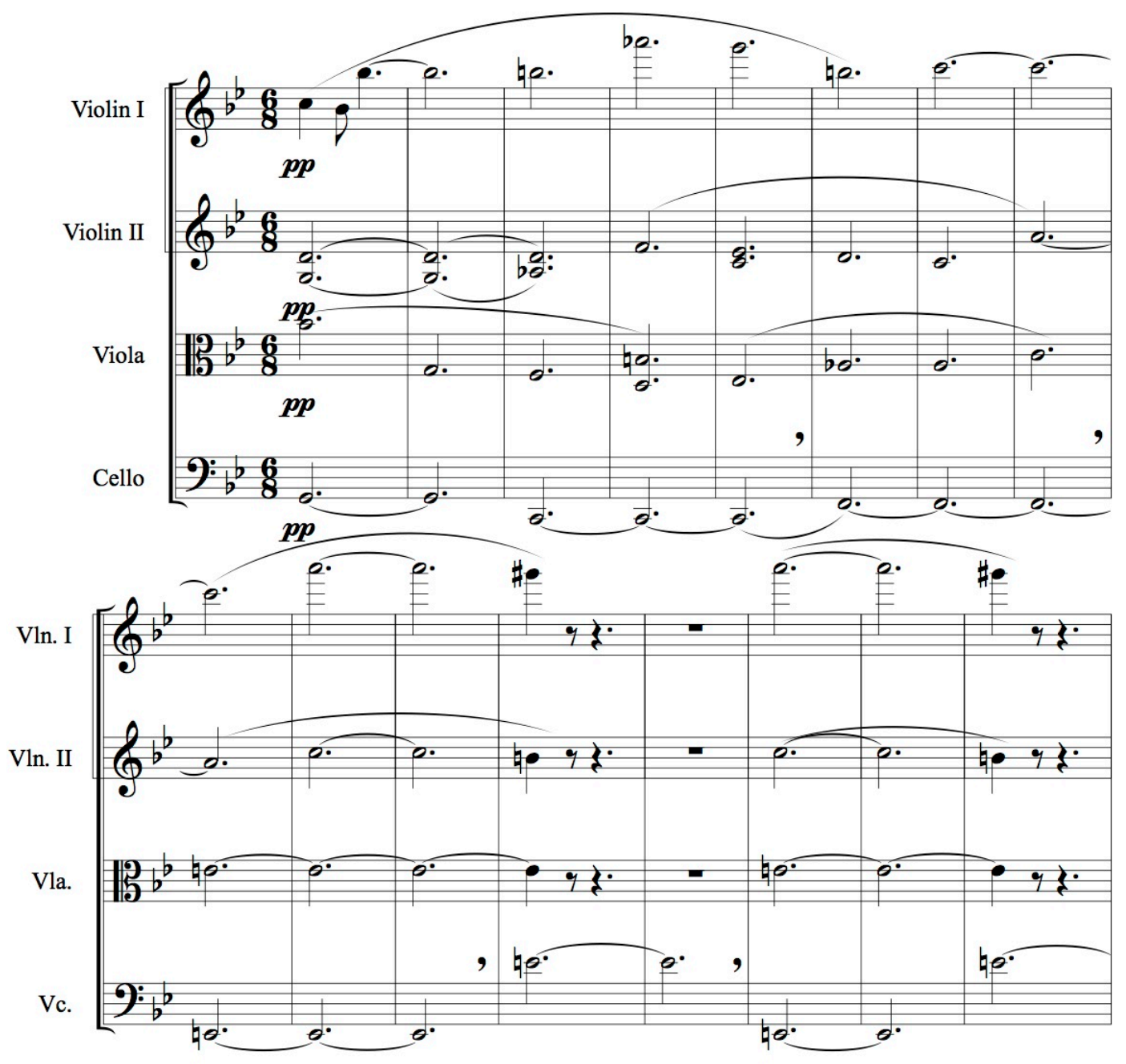




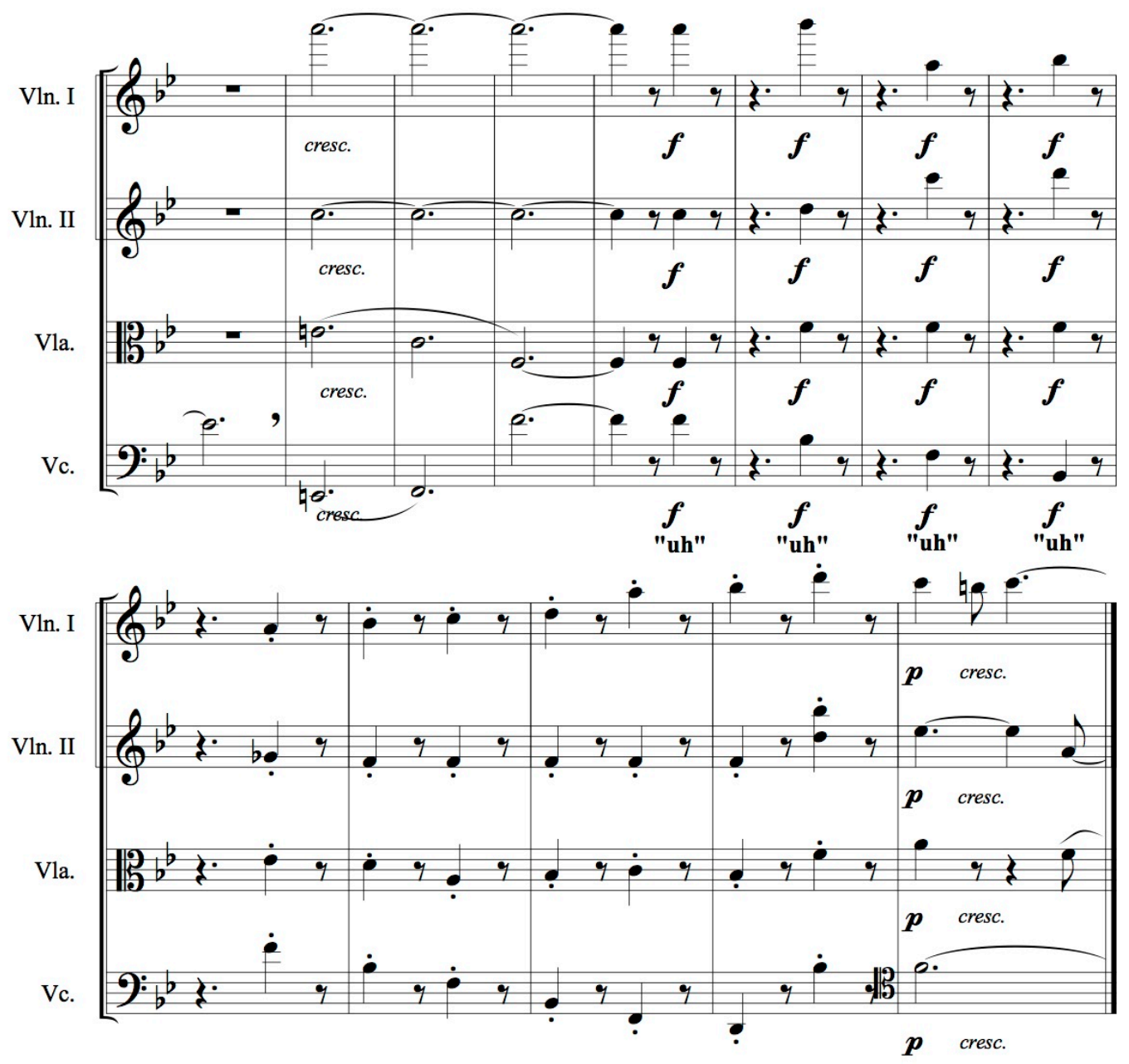

FIGURE 1: Ludwig van Beethoven, Grosse Fuge, mm. 609-637. The breath marks in the cello part represent the audible sounds of breath on the Guarneri Quartet's recording.

Regardless of the attribution of breath sounds within the Grosse Fuge, these bodily sounds serve a critical authenticating function for the recording, and they do so on several levels. The breaths might be considered part of the quartet's system of 'leads', the cues that one member of the group gives to the others to coordinate articulations and entrances. The Guarneri players described themselves as a "leaderless quartet", and they therefore developed some very subtle cues to communicate with each other (Blum 1986: 10). In part, their system of "leads" was developed from their awareness of the visual component of concert performance; violinist Arnold Steinhardt observed: "It's important not to allow our gestures to distract from the line of the music. Whether we like it or not, the audience takes in the visual part of the experience" (ibid). Moreover, the quartet emphasized that unlike many chamber ensembles, they do not look at each other. As Steinhardt noted: "To actually look at John [Dalley] I would have to turn my back to the audience. I don't have to see his expression - inspiring as it may be but I must be able to see his bow and, above all, the fingers of his left hand" 
(Blum 1986: 14). Steinhardt's wording in these matters suggests that the Guarneri players have perhaps compromised their ideal way of cuing each other for the sake of presenting a unified image to the concert audience.

Conceivably, the recording studio offers the Guarneri Quartet a context where they can play unencumbered by visual considerations. However, this was not the case. Cellist David Soyer described the experience noting that:

It's a sterile situation; the setting is antimusical. There's no audience; you're playing to a battery of microphones. The process is corrupting. You play a piece many times; the mikes aren't right, the balance isn't right, there may be mistakes, you're unhappy with something. And as you make takes of a movement over and over again, your perceptions begin to alter. What you would have at first considered a good tempo may seem too slow because you've heard it so many times. So on the finished version we may end up doing something that's glib - because it's take number ten. (Blum 1986: 2021)

Like a great many classical musicians, the Guarneri Quartet objected to what they saw as an artificial construct for a musical performance. The recording studio is necessary, as recording has become a ubiquitous part of contemporary musicmaking. However, many classical musicians share the Guarneri's view of studio work as necessary but musically unsatisfying. ${ }^{6}$

The Guarneri musicians spoke very little about their artistic process in the recording studio. Nonetheless, I argue that the corporeal elements of their recordings - the breaths and grunts that mark the close of the Grosse Fuge - serve a critical role in conveying their conception of the musical works they recorded. The breaths and grunts are important not despite, but because of the lack of visual elements in the recording context. ${ }^{7}$ In concert, the quartet's leads might happen silently (or at least without the audience paying much mind to them, against the rest of the music). In the recorded context, however, the leads are laid bare for us to hear. These breaths and grunts are an example of Sanden's "corporeal liveness", the traces of the "acoustic sounding body" that verifies the authenticity of the performance (Sanden 2013: 11). These breaths and grunts verify the musicking bodies and in doing so form a critical component of the recorded performance - helping to convey the quartet's sense of the Grosse Fuge's architecture and their own "Herculean" grappling with its physical challenges.

Furthermore, the corporeal traces on the recording are not (or at least not only) generally musical; they are also particular to the time and place of the recording. If we listen closely to the Grosse Fuge passage described above, we can not only hear the audible breaths from Soyer (or whomever) before several notes; we can even hear a bit of a flutter in the final breath of the passage, evidence of a partially obstructed nasal passage. Such a detail speaks directly to the particulars of the musicians at the moment of the recording, not merely verifying the corporeality of the performance and the musical concept of the performers, but also revealing the unique imperfections of Soyer's body, in his sinus cavity, on the day the recording was made. Such a sonic trace has a unique life on recording because of its singularity. 
Replication of that precise moment when Soyer took his fluttering breath is rather beside the point, at least from a recording standpoint. The presence of the quartet's breaths and grunts tell us virtually nothing about the technological processes by which the recording of the Grosse Fuge was produced. We cannot know from these details to what extent the recording is a composite of several different takes, who made the decisions to retake and edit the recording, etc. Furthermore, we do not know whether any effort was made to conceal the musicians' breathing and vocalizations during the recording process. While the musician's inhaling and grunting could not have been excised technologically from the recording - at least, as easily as they might be today - the musicians and recordists surely were aware of those sounds on the recording and could easily have created a breath-free recording through retakes and patches, had they chosen to. Regardless of the musicians' and recordists' intent, the breaths and grunts ultimately validate and authenticate the recorded performance, particularly in the absence of the visual cues - dramatic gestures, violent bow strokes, sweating musicians - that audiences have in concert performances. Thus, these corporeal sounds serve to verify what have traditionally been core tenets of Western classical music: the singular, unified performance and the expression of the composer's intention (with the performer as vessel for that intention). ${ }^{8}$

\section{Track 2: Colin Stetson, "Hunted"}

I saw saxophonist Colin Stetson perform in Chicago in 2014. The performance was extraordinarily physical - as one would expect from a performer who specifically writes in the liner notes of his records: "All songs written, performed and recorded live without overdubs or loops by Colin Stetson" (Constellation 2013). Stetson seems to claim that through the mediation of the recording we are experiencing his real musicking body, and that the recording is simply a vessel that conveys the body to the listeners. Indeed, after about 45 minutes of playing nearly continuously at the Chicago concert, Stetson apologized for the brevity of his set, explaining that his songs take a lot out of him. He played a final song, thanked the crowd, and departed the stage (Stetson 2014).

In some regards, Stetson's use of breath is consistent with the Guarneri Quartet. Like the Guarneri, Stetson's breathing is indexical of the musical sound he produces - especially considering that breath is an essential precursor to the production of sound on the saxophone. The distinction I am making here is not that a saxophonist like Stetson must breath while string quartet players like the Guarneri musicians need not do so; nor is it the case that one's breathing is necessarily more tied to the musicality of the performance than the other. However, as a saxophonist Stetson must contend with the fact that breathing must be an element of his instrumental technique, as the air he exhales is vibrated in the saxophone to produce sound. I contend that one of the more remarkable elements of Stetson's musical performance is that he has taken the acoustic and physiological necessity of breath and transformed it also into an element of his complex musical polyphony.

Stetson's performances - including one I witnessed (Stetson 2014) and others that can be viewed online (for example, see Stetson 2013, 2015) - employ 
practically his whole body. He slams the keys of his instrument to create a percussive sound. He alters his air stream (what he calls "voicing") in order to produce multiphonics in the saxophone's upper (altissimo) register. He sings countermelodies to the instrumental parts. And he assembles these across a continuous (and often lengthy) performance by employing circular breathing. ${ }^{9}$ These techniques, especially in combination, are physically taxing, no less so when one considers that one of Stetson's primary instruments is the very large 20pound bass saxophone. At the same time, Stetson is quite savvy with his use of amplification and recording technologies. The massive cavity of the bass saxophone is well suited to resonate the slapping of keys, but it doesn't project far enough to be heard acoustically in concert or with a normal microphone. Consequently, Stetson uses contact microphones attached to the back of his instrument to capture the sound of the keys. Similarly, his singing would not project enough over the other elements of his playing, so he wears a microphone on a collar. In at least one photo I have seen (Singh 2011), Stetson has yet another microphone positioned near his mouth while playing (which is in addition to the expected microphone in front of the saxophone bell) in order to capture the sound of his breathing. (For an example of Stetson's performance techniques, see Stetson 2011).

In short, Stetson's recorded performances, while "live" in the sense of having been played continuously ("without overdubs or loops", Constellation 2013), are substantially a product of Stetson's microphone techniques. I use the phrase "microphone technique" here specifically to refer to the ways in which musicians have adapted their singing and playing styles to the possibilities of the microphone - the most famous of which is perhaps the "crooning" vocal style that developed in the late 1920s in response to the advent of the microphone and electric recording. ${ }^{10}$ In Stetson's case, the microphone is a key collaborator in his musical process: it allows him to create a polyphonic music that would not be possible (because several elements would not be audible) without the ability to capture these many layers through close miking. ${ }^{11}$

Furthermore, Stetson is highly conscious of the role of breath as a part of his musical performances. In an NPR interview he remarked, "Everything I do is intended to be music. The breathing is all part of that" (NPR 2011: web source). He also elaborated on his circular breathing technique:

I learned when I was about 15 . My teacher at the time, he taught it to me as a means to perform string pieces. So string players don't have to breath. When we would play them, our phrasing would always be interrupted by our breath. So he taught me this... Your brain just figures out how to do it and your body follows along. (ibid)

Stetson positions his breathing as simultaneously a means to an end and an aesthetic sonic element, even though these two views did not develop simultaneously. In learning to circular breath, Stetson describes the challenge as primarily conceptual, and the body as subservient to the mind. However, once the technique is adequately developed, then Stetson has greater freedom to use it as an expressive device, to make breath a part of his sonic palette while still using it to create extended continuous musical performances. The result is a seemingly 
paradoxical mix of humanness and superhumanness, a paradox that has long been a part of discourses of virtuosity (for example, see Deaville 2014; Kramer 2012). In Stetson's case, the sound of breath points to the physicality of the performance and the rigor with which Stetson has trained his musical body, while the unending performances seem to defy what is physically possible.

Stetson's breathing techniques are evident throughout his recorded corpus, although here I will only analyze the track "Hunted" from his 2013 album New History Warfare Vol. 3: To See More Light. In "Hunted" Stetson constructs a work that proceeds in alternating phrases of four long beats. Over a constant low ostinato, Stetson sings a descending melodic line, picked up by his throat microphone and paralleled in the multi phonic counterpoint of the saxophone. In a consequent phrase, Stetson maintains the ostinato while loudly inhaling four times through his nose. The inhales are not quite evenly spaced to align with the beats; there are three substantial inhales and one final quick one before the antecedent phrase enters again (see FIGURE 2). This pattern of antecedent and consequent phrases repeats throughout the song, and importantly, Stetson's breathing remains nearly identical in rhythm and timbre throughout. In the song's middle portion, the overall dynamic level decreases, allowing Stetson to double the length of the antecedent phrases. Nonetheless, in the consequent phrases which are the same length as the opening - Stetson's breathing pattern is identical, containing three long nasal breaths and one short one.

A hybrid of Stetson's musicking body and his studio technique, in "Hunted" we see how crucial the recording medium is for Stetson, even though he does not overdub or cut together different takes. Because he uses several microphones focused on different parts of his musical body and instrument, he is able to process different components of his counterpoint distinctly from each other. For example, the reverb on "Hunted" indicates that Stetson's singing is quite distant because it is drenched in reverb and yet perceptually seems energetic and "loud". This indicates to the listener that Stetson's singing does not occupy the same physical space as his saxophone which sounds dryer, and is therefore heard as closer to the listener. ${ }^{12}$ His description of his recording practices in the liner notes seems designed to dispel listeners' potential anxieties at the authenticity of his performance. He seems to anticipate that his recorded performances are likely to be heard and interpreted within a mediatized listening culture (Auslander 2008) and that listeners will therefore have a skepticism, born of the ubiquity of recording technology, about his real physical ability to produce the music on the recording. However, this dichotomy is not a real one - or, to be more precise, it is not the case that we must see Stetson's performance as either a singular musicking body or technologically enabled. Stetson uses recording technologies to further extend his already extended bodily techniques as a means of building an intimacy with listeners who are able to experience his bodily counterpoint from a simultaneously close and distant perspective. 

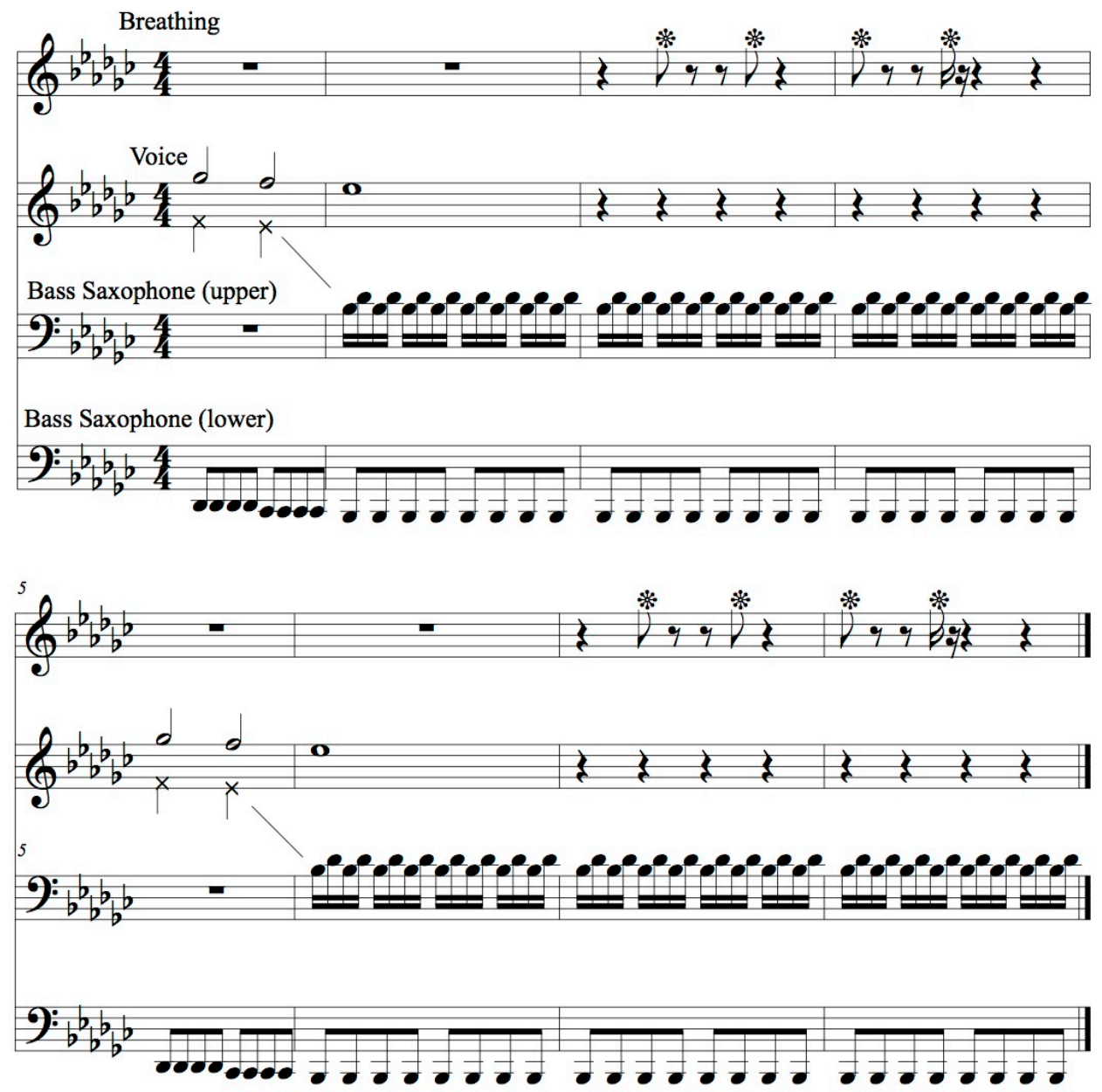

Figure 2: Colin Stetson, "Hunted", opening. The upper part is sung in a "pure" tone, while the lower one is heavily distorted, making the pitches unclear (and hence the " $x$ " note heads). The starred note heads indicate where Stetson inhales audibly through his nose, including approximate lengths of the breaths (three long and one short), and they are represented on a separate staff to emphasize their role in the song's polyphony.

Compared with David Soyer and the Guarneri Quartet, Stetson's breathing is striking and extreme, although less so than one might initially expect. These are all musicians for whom breathing relates intimately to their musical performance. In both cases, breath is a way of articulating phrase structures with the music, although for Soyer, breath is not present on the recording as a deliberate sonic and musical element. Soyer's breathing was likely the by-product of his musical performance in the studio (and, as we saw above, also the result of the quartet and recordists trying to strike a balance between achieving perfection and preserving the "take-oneness" of the recording). In contrast, Stetson seems to want to transcend the necessity of breathing that has traditionally been a limitation for players of his instrument. As with Soyer, Stetson's audible breathing serves to mark the extraordinary physicality of his musicking; but unlike Soyer, Stetson consciously controls, places, and dynamically balances his breathing in order to enhance the contrapuntal features of his music. 


\section{Track 3: Miley Cyrus, "Wrecking Ball"}

I isolated the breath taken by Miley Cyrus immediately before she launches into the final chorus of her 2013 hit song "Wrecking Ball". On its own, the breath sounds quite unnatural: it is loud and seems to crescendo to a peak right before Cyrus sings the words "I came in like a wrecking ball" (RCA 2013). Its sonic envelope perhaps resembles a human breath far less than it does a carefully constructed studio effect like the backwards cymbal on the Beatles' "Strawberry Fields Forever" (Parlophone 1967). ${ }^{13}$ However, despite its apparently unusual shape, the breath fits easily in the context of the recording, as it is rhythmically consistent with the rest of the sequence of five eighth-note pick-ups, serving as the sixth pick-up (see FIGURE 3). Additionally, it matches Cyrus's singing voice dynamically. These features suggest that the sound of Cyrus's breath was consciously treated as a constituent sound by the recordists who worked on the track. Analyzing the breath's dynamic shape using Sonic Visualizer (see FIGURE 4), shows that the breath grows in intensity such that it flows easily into Cyrus's articulation of the word "I". The breath's dynamic peak is not as high as the succeeding vocal, but it is higher than the preceding vocal passage, an exposed and quiet interlude accompanied only by piano.

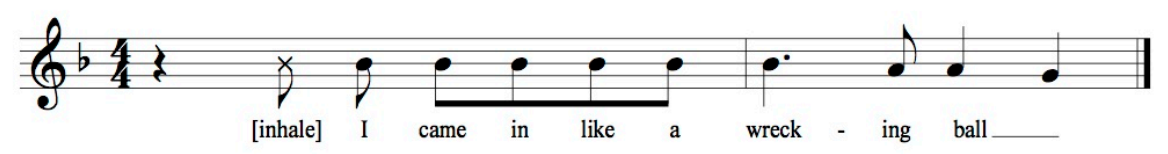

FIGURE 3: The breath and opening of the final chorus of "Wrecking Ball", recorded by Miley Cyrus. This passage is found at 02:50 in the recording.

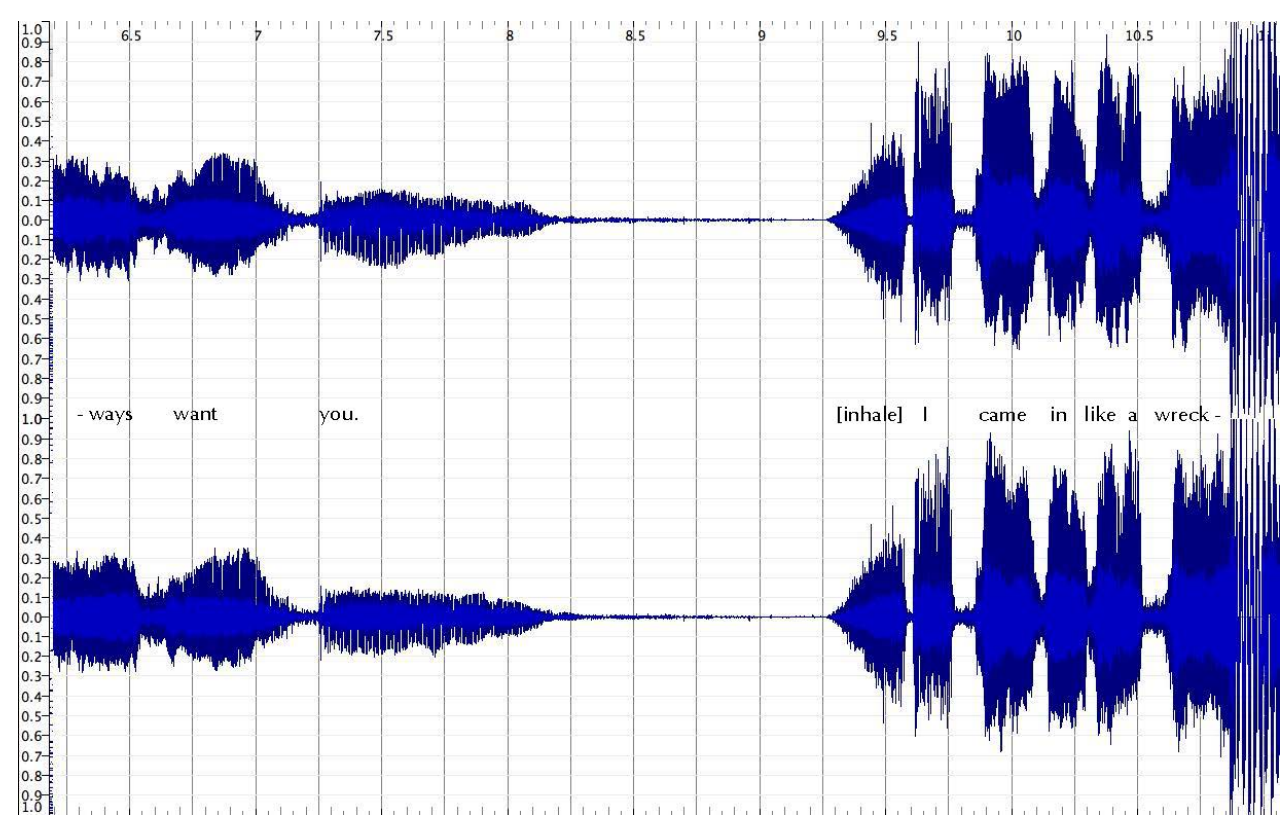

FIGURE 4: The relative dynamic levels (using Sonic Visualizer) of the end of the bridge and the beginning of the final chorus of "Wrecking Ball", sung by Miley Cyrus (approximately

02:47-02:52 in the track). The lyrics are overlaid on their respective components of the visualization. The height of the lines represents dynamic intensity. 
The breath seems to have been compressed along with the rest of the vocal, a process that would have made it more audible and altered other sonic properties associated with it (such as its timbre). Compression is a technique that, in the words of one recording handbook, "stabilizes the image of the sound" on the recording "by evening out the volume peaks on a sound" (Gibson 2005: 79). This, in turn, allows a recordist to "turn up the overall volume and put the whole sound right in your face" (Gibson 2005: 80). ${ }^{14}$ Thus, the sound of a breath - say, Cyrus inhaling - can be made to closely match the dynamic of the surrounding vocals using compression. It is hardly surprising that Cyrus's vocal would be substantially compressed on the recording of "Wrecking Ball", since this is a standard technique in pop music recording. However, the compression of the breath is interesting if we consider it within the context of recording as a process which constructs and authenticates the musicking body.

A quick and unscientific comparison between the studio recording of "Wrecking Ball" and Cyrus's live performance of the song at the 2013 iHeartRadio Festival reveals that the studio recording is notable for its polished, even vocal (Cyrus 2013). In her live performances of the song, Cyrus's vocals are a bit wobblier, as one would expect, and her breaths are usually inaudible. Cyrus typically drops her hand-held microphone to her side between lines, thus making her breathing inaudible to the audience. The contrast between the live and recorded versions is not simply a reflection of the technological contexts, rather, this contrast points to the different expressive forms employed by Cyrus. Within the song's structure, the moment before the entrance of the final chorus is marked as particularly expressive and intimate. Cyrus sings a line from the latter half of the song's verses: "Don't you ever say I just walked away. I will always want you" (RCA 2013). In concert performances of "Wrecking Ball", Cyrus uses the moment in the song to convey vulnerability through her body, making gestures with her arms, employing her facial expressions, and perhaps even crying (Cyrus 2014).

In contrast, the studio recording does not have a visual component with which Cyrus can convey meaning and emotion to audiences, and consequently, all of this emotion must be directed towards the sonic construction of Cyrus's performance. On the recording, she sings the critical pre-chorus line with (apparently) the same level of dynamic intensity as in the earlier verses, yet this moment in the song (at 02:41) stands in contrast to the rest of the track for its spare accompaniment, consisting solely of a barely audible piano. The staging makes Cyrus's persona seem vulnerable, and it stands in stark contrast to the dense texture and assertive, belted vocal that follows. The sound of the breath, while expressively extraneous in a concert performance, serves an essential function in representing the emotional vulnerability and strength of Cyrus's recorded persona. The breath is the one sound in this recording that listeners are sure to recognize as "human" - including even Cyrus's voice, which, through studio processing, seems rather technological, particularly compared with her concert performances. Moreover, the staging of the breath in this way is not necessarily part of a broader process of pop music production, or even of the production of Cyrus's other recordings. Nowhere else on Bangerz, the album featuring "Wrecking Ball", is Cyrus's breath nearly so prominent. Instead, the highly audible breath is part of the expressive apparatus of this track in particular; 
it sonically conveys Cyrus's humanness using the technological procedures that give the track its identity.

At the same time, the studio construction of humanness via the sound of breath in "Wrecking Ball" highlights a particular difficulty for female performers in the recording medium. Cyrus's vocal on this track presents her as what Jennifer Fleeger (2014) has called a "mismatched woman", a mediated presentation of a woman's voice that assures listeners of the authenticity and wholeness of the woman's musicking body. For Fleeger, the concept of the mismatched woman "arises from the rift between the rhetoric of fidelity that accompanies the introduction of new sound machines and the dissociation of body and voice they require to function" (Fleeger 2014: 6). The mismatched woman is a particular sort of "schizophonia" (Feld 1994; Schafer 1977), a term that is generally understood as the separation of sound and source that is inherent in the recording medium the schizophonia of the mismatched woman is inflected by the gendered discourses of sound (re)production that characterized recording from at least the early 20th century. In the case of contemporary pop production, this means that female performers are often limited to a handful of sonic self-presentations, and that their status as creative agents is substantially circumscribed.

These limitations are tied to a broader suspicion of the technological resources of record production, particularly as they apply to female artists. Kay Dickinson observed with regards to Cher's vocals on "Believe" (1998),

Certain vocal conceits are cherished as exceptionally direct conduits to the core of the self, to some sort of emotive truth, with Bob Dylan's scratchiness or James Brown's grunts winning more of these types of prizes than the smooth, non-grating and physically less aligned vocal offerings of the likes of ABBA. (Dickinson 2004: 166)

The cultural preference for the apparently less mediated and less refined vocals of male singers assures that the conventional vocal production found in recordings of female pop singers will not be seen as properly "musical". This is precisely what Emma Mayhew found in critiques of Kylie Minogue's recordings, which deemphasized her vocal abilities in favour of the technological work of her (male) producers (Mayhew 2004: 154-155). Similarly, Liz Greene observes that female vocals are often recorded in a close-up perspective without reverberation, "allowing listeners to feel unrealistically close to the singer, as if the performer is whispering to them" (Greene 2009: 64). Importantly, this close perspective not only facilitates, but requires, that listeners are able to hear the female performer breath on the recording.

In an apparent paradox, the sorts of technological transformations of female voices described by Fleeger and others are seen as simultaneously authentic and devalued. Female pop vocals fit into prevailing discourses about the voice as the sonic expression of the human soul while also being judged inferior to (male) vocals that are perceived as less mediated. ${ }^{15}$ We can easily hear many of the characteristic production techniques in Cyrus's vocal on "Wrecking Ball": the double-tracked voice in the chorus, the various transformations of her voice to construct backing vocals, the almost certain use of ubiquitous Auto-Tune and compression technologies. By not only severing the sound of the voice from the 
body that produced it, but also splintering that voice into multiple individual parts, these techniques ensure a "mismatch" between Cyrus's body and her voice. That mismatch is further highlighted by the substantially different vocal qualities displayed by Cyrus in concert performances. However, the presence of Cyrus's breath cuts against these trends, challenging the idea that her singing is one of "the smooth, non-grating and physically less aligned vocal offerings" (Dickinson 2004: 166) that are perceived as inauthentic, and thus, restoring a trace of Cyrus's musicking body to the recording.

Cyrus's status as a mismatched woman is seen further in the disparity between the authenticity claims made by "Wrecking Ball" and Colin Stetson's "Hunted". For Stetson, the sound of breath (as a studio construction) verifies the explicit claim in his liner notes that his body is coherent, that it produced all of the sounds on the record in real time. In contrast, "Wrecking Ball" makes no such claim because, by convention, pop music audiences do not require it of female pop stars. The heavily processed sound of breath on the recording of "Wrecking Ball" conveys a musicking female body - but without the suggestion or requirement that there be a corresponding "real" musicking body that is capable of reproducing those sounds "live". Cyrus uses entirely different expressive means to convey her authenticity as a performer in a concert setting, highlighting rather than concealing the distinction between her body as a recorded construction and as a physical presence.

\section{Conclusion}

The three cases discussed in this article seek to demonstrate that the sound of breath on a recording points to the processes of mediation and creativity that define record production. Naturally, the sounds of breath vary substantially between records of different musical genres, historical moments, and cultural contexts. Sometimes, breath may be ontologically insignificant, as in the case of the Guarneri Quartet, where the sound of the players inhaling and grunting is merely a by-product of their attempt to render a faithful and convincing interpretation of a musical work. In other instances, musicians and recordists might not only be aware of the sound of breath, but also actively capture, position, and manipulate it as a constitutive sonic element, as in the case of Colin Stetson's multi-layered bodily polyphony. The case of Miley Cyrus indicates that the recording studio processing of breath sounds can form a part of an overall mediatisation of the body.

However, by attending to the sound of breath on these recordings, we can glimpse beneath the apparently coherent surface of the recording to view record production as an inherently distributed creative process. That creative process constructs the musicking body that is presented on the recording as a singular entity. However, the coherence of the musicking body on the recording is often illusory, the confluence of ablist assumptions about coherent bodies and persistent post-Romantic ideas regarding vocal expression. Moreover, the presence of a voice on a recording might not be taken as representative of a musicking body at all, and it is breath that restores the humanness of the 
performance. ${ }^{16}$ These three recordings indicate that the recorded musicking body is always a technologically constructed one, and our attention to breath might highlight the nature of that construction in ways that are not always available by attending to the voice alone. As the nominal "excess" of voice, the physiological process that is essential but not considered expressive, breath ultimately acquires and expressive power of its own. It points to the body as a mediated presence on a recording, perceived as whole and authentic, and yet turning out to be distributed and fragmented on closer examination. It is my hope that in future years, we will see more attention to the breath as an expressive device along with the more traditional tools of musical performance.

\section{Endnotes}

${ }^{1}$ Christopher Small coined the term "musicking" to highlight the disjunction between the Western conception of music as a thing (the musical "work") and music as "an activity, something that people do" (Small 1998: 2). Small argued that "musicking" should be broadly inclusive. He wrote, "to pay attention in any way to a musical performance, including a recorded performance, even to Muzak in an elevator, is to music" (Small 1998: 9). I use the term "musicking" here explicitly to expand the sometimes narrow bounds of what is properly considered "musical" about the voice.

2 Richard Middleton recognizes the connection between voice and breath, with the latter's "continuity of life [and] periodicity of organic processes" contributing to the perception of voice as "the profoundest mark of the human" (Middleton 1990: 262). While Middleton talks at some length about the voice and the "pleasures of the body" in popular music recordings, he does not elaborate on this fleeting reference to breath. Adriana Cavarero, in her critique of the subordination of voice to thought in the Western philosophical tradition, also acknowledges the intimate connection between voice and breath. She argues that "prior to the triumph of metaphysics, the Greeks were thus convinced that thinking was done with the lungs, not the brain" (Cavarero 2005: 63). In Plato, Cavarero finds that a shift has occurred in the conceptualization of thinking, moving from lungs to head, resulting in "the prevalence of head over lungs", as well as the movement of "the measure of the human being from the physicality of the body to the impalpability of the mind" (Cavarero 2005: 65). While Cavarero's argument will have little impact on my own treatment of breath in the remainder of this article, her profound insights about the process by which voice became subordinate may, at least, provide some explanation for the relative dearth of scholarship on the topic of breath.

${ }^{3}$ Many thanks to Josh Sacco, recording engineer at Davidson College, for explaining to me how breaths can now be removed digitally, but how they also were commonly excised from tape recordings, particularly of spoken word recordings. The minute cut to remove a breath was then replaced with an identically-sized piece of blank tape to maintain the flow or rhythm of the speech on the recording.

${ }^{4}$ Following Fabian Holt (2007), I use the term "genre culture" to refer to the broad social and cultural networks and relationships through which musical sound is classified and organized. Thus, I do not necessarily wish to argue that particular musical forms are inherently suited to particular technological interventions in the studio - although this often seems to be the case to practitioners of a particular musical genre. Rather, I assume that the recording conventions for a genre are flexible and always subject to (re)negotiation based on the particular aesthetic sensibilities of recording session participants. 
${ }^{5}$ Unsurprisingly, the debate over which is the "correct" ending for the quartet tends to turn on the role of that often-unwelcome facilitator of artistic creation, money. As Lewis Lockwood describes the debate, one side relies on the historical fact of Beethoven's decision to sever the Grosse Fuge, while the other side argues that the financial motivation presented to Beethoven corrupted his otherwise pure artistic intentions. For present purposes, we need not delve any deeper into the conflict - although I tend to agree with Lockwood that the debate is rather irrelevant for anyone except a quartet who performs op. 130 (see Lockwood 2003: 458-468).

6 The most notable exception is Glenn Gould, against whom the Guarneri position themselves: while Gould valued the artistic possibilities of making multiple takes and editing them together, the Guarneri prized the "take-oneness" of concert performance (Blum 1986: 21).

${ }^{7}$ The visual analogy of recording perhaps originates with Decca producer John Culshaw, who conceived of using the possibilities of the long-playing record and stereophony to convey the action of operas through sound alone, and often in ways that were more sonically suggestive than would be evidence in a staged performance. Culshaw observed, "The effect [on record] is nothing like that of the theatre ... The sense of being inside the drama is heightened by the absence of a visual element: the listener can hear the words and the music, he can hear where the characters are standing and he can follow them when they move; but he has to create his own mental image of what they look like, and in what sort of setting they are moving. Instead of watching someone else's production, he is unconsciously creating his own" (Culshaw 1967: 23-24).

${ }^{8}$ Christopher Small has observed that, in Western art music, "a musical performance is thought of as a one-way system of communication, running from composer to individual listener through the medium of the performer" (Small 1998: 6). This notion of musical performance effectively denies any interpretive agency by musicians who perform musical works, reifying and continually reinscribing what Lydia Goehr (1992) has famously called the "work-concept". I argue that by attending to the breathing of a performer like Soyer, we can better understand how the hegemonic "work-concept" functions in practice, discursively erasing the musician's presence from the performance even as we are made aware of it.

${ }^{9}$ Circular breathing is a technique that can be employed on virtually any wind instrument in which the player inflates her cheeks and then allows that air in her mouth to flow through the instrument and briefly produce sound, while inhaling through the nose. Circular breathing can allow a wind player to continue to produce sound virtually infinitely.

${ }^{10}$ The technique of crooning has been explored at length by Allison McCracken (2001; 2015), who highlights how the recording and singing techniques worked hand-in-hand for performers like Rudy Vallee and Bing Crosby, and how crooners were perceived as sexually threatening. Serge Lacasse has positioned crooning within a broader concept of "staging" in recorded music - the ways that contextual sonic information like reverb shapes how listeners perceive the voice (Lacasse 2000; 2010; see also Zagorski-Thomas 2010).

${ }^{11}$ Stetson has described and demonstrates these performance and microphone techniques in relation to his song "Judges", on the Canadian radio show Q (Stetson 2011).

${ }^{12}$ Reverb has long been recognized as a core component of sound recording, and it has recently been analyzed by Albin Zak (who refers to it as "ambience"; 2001: 76-85) and Peter Doyle (2005). Reverb on a recording conveys the space occupied by one or more 
musical elements of the recording, and the listener's relative position within that space. A large amount of reverb - and consequently, a proportionally lower amount of direct sound - conveys a greater distance between the listener and the sound source. Importantly, listeners perceive loudness independently of reverb, because the perception of loudness depends in large part on timbre, and it relies on listeners' intuitive ability to recognize "the amount of physical exertion required to produce a certain sound quality on an instrument" (Moylan 2015: 169). Thus, a recorded sound can simultaneously be perceived by listeners as loud and distant - having a relatively low dynamic level, a proportionally large amount of reverb, and the perception of intensity in the performance.

13 This effect, which appears during the second verse of "Strawberry Fields Forever" (at about 01:25), was produced by recording the cymbal in isolation and then reversing the tape. The result is a "shoop" sound that begins with the diffuse ringing of the cymbal and builds quickly to a dynamic peak where the cymbal was struck. The technique is described by engineer Geoff Emerick (Emerick and Massey 2006: 135).

${ }^{14}$ To be clear, I am not necessarily claiming that Cyrus's breath was processed with a compressor - although that seems to me the most likely possibility - but rather, that her breath was compressed in the more general sense that its amplitude was manipulated so that it closely matched that of the succeeding vocal entrance (as illustrated in FIGURE 4). Importantly, although compression is initially a technique that lowers the level of dynamic peaks in a recording, it does not necessarily mean that a recording will have a lower overall dynamic level, because a compressed recording can then have its overall level boosted. For this reason, compression has been a common explanation for the socalled "loudness war" that has been observed in metal music (Williams 2014) and also popular music recordings more broadly (for example, Devine 2013).

${ }^{15}$ In contrast to the close perspective of female pop vocals, Greene notes that "men's voices are not usually recorded in such an intimate manner. Rather, they are usually recorded with a spatial distance from the microphone allowing their voices to embody a space containing reverberation" (Greene 2009: 64).

${ }^{16}$ This is what Paul Sanden suggests when, writing about the appearance of breathing within Glenn Gould's inadvertent vocalizing, he writes, "the voice we hear on these recordings is not just an ethereal humming sound, but it has a source: a living, breathing body" (Sanden 2013: 57).

\section{References}

\section{Bibliography}

Abbate, C. 1999. Outside Ravel's Tomb. Journal of the American Musicological Society 52(3): 465-530.

Auslander, P. 2008. Liveness: Performance in a Mediatized Culture. London: Routledge. Second edition.

Barthes, R. 1977. Image-Music-Text. New York: Hill and Wang. Translated by Stephen Heath.

Blum, D. 1986. The Art of Quartet Playing: The Guarneri Quartet in Conversation with David Blum. New York: Alfred A. Knopf. 
Brooks, P. 2000. Body and Voice in Melodrama and Opera. In M.A. Smart Ed. Siren Songs: Representations of Gender and Sexuality in Opera, Princeton: Princeton University Press: 118-134.

Cavarero, A. 2005. For More than One Voice: Toward a Philosophy of Vocal Expression. Stanford: Stanford University Press.

Culshaw, J. 1967. Ring Resounding: The Recording in Stereo of Der Ring des Nibelungen. London: Secker and Warburg.

Deaville, J. 2014. Virtuosity and the Virtuoso. In S. Downes Ed. Aesthetics of Music: Musicological Perspectives. New York: Routledge: 276-296.

DeNora, T. 1995. Beethoven and the Construction of Genius: Musical Politics in Vienna, 1792-1803. Berkeley, CA: University of California Press.

Devine, K. 2013. Imperfect Sound Forever: Loudness Wars, Listening Formations and the History of Sound Reproduction. Popular Music 32(2): 159-176.

Dickinson, K. 2004. "Believe": Vocoders, Digital Female Identity and Camp. In S. Whitely, A. Bennett and S. Hawkins Eds. Music, Space and Place: Popular Music and Cultural Identity. Aldershot: Ashgate: 163-179.

Dolar, M. 2006. A Voice and Nothing More. Cambridge: The MIT Press.

Doyle, P. 2005. Echo \& Reverb: Fabricating Space in Popular Music Recording, 1900-1960. Middlebury, VT: Wesleyan University Press.

Emerick, G. and Massey, H. 2006. Here, There, and Everywhere: My Life Recording the Music of the Beatles. New York: Gotham Books.

Feld, S. 1994. From Schizophonia to Schismogenesis: On the Discourses and Commodification Practices of "World Music" and "World Beat". In C. Keil and S. Feld, Music Grooves: Essays and Dialogues. Chicago, IL: University of Chicago Press: 257-289.

Feldman, M. 2015. The Interstitial Voice: An Opening. Journal of the American Musicological Society 68(3): 653-659.

Fleeger, J. 2014. Mismatched Women: The Siren's Song Through the Machine. Oxford: Oxford University Press.

Frith, S. 1996. Performing Rites: On the Value of Popular Music. Cambridge, MA: Harvard University Press.

Gibson, David. 2005. The Art of Mixing: A Visual Guide to Recording, Engineering, and Production. Boston, MA: Thomson Course Technology.

Goehr, L. 1992. The Imaginary Museum of Musical Works: An Essay in the Philosophy of Music. Oxford: Clarendon Press.

Greene, L. 2009. Speaking, Singing, Screaming: Controlling the Female Voice in American Cinema. The Soundtrack 2(1): 63-76.

Holt, F. 2007. Genre in Popular Music. Chicago, IL: University of Chicago Press.

Kassabian, A. 2013. Ubiquitous Listening: Affect, Attention, and Distributed Subjectivity. Berkeley, CA: University of California Press.

Kramer, L. 2012. The Virtuoso Body; Or, the Two Births of Musical Performance. In S. Hawkins Ed. Critical Musicological Reflections: Essays in Honour of Derek B. Scott. Aldershot: Ashgate: 231-244.

Lacasse, $\mathrm{S}$.

2000. "Listen to My Voice": The Evocative Power of Vocal Staging in Recorded

Rock Music and Other Forms of Vocal Expression. Liverpool: University of

Liverpool. Ph.D. thesis. 
2010. The Phonographic Voice: Paralinguistic Features and Phonographic Staging in Popular Music Singing. In A. Bayley Ed. Recorded Music: Performance, Culture and Technology, Cambridge: Cambridge University Press. 225-251.

Lockwood, L. 2003. Beethoven: The Music and the Life. New York: W.W. Norton and Company.

Mayhew, E. 2004. Positioning the Producer: Gender Divisions in Creative Labour and Value. In S. Whitely, A. Bennett and S. Hawkins Eds. Music, Space and Place: Popular Music and Cultural Identity. Aldershot: Ashgate: 149-162. McCracken, A.

2001. Real Men Don't Sing Ballads: The Radio Crooner in Hollywood, 19291933. In P. Roberson Wojcik and A. Knight Eds. Soundtrack Available: Essays on Film and Popular Music. Durham, NC: Duke University Press.

2015. Real Men Don't Sing: Crooning in American Culture. Durham, NC: Duke University Press.

Middleton, R. 1990. Studying Popular Music. Milton Keynes: Open University Press.

Miller, R. 1997. Nose or Mouth Breathing? Journal of Singing: The Official Journal of the National Association of Teachers of Singing, Inc. 53(3): 37-40.

Moylan, W. 2015. Understanding and Crafting the Mix: The Art of Recording. New York: Focal Press. Third edition.

NPR 2011. Colin Stetson: Horn of Plenty. http://www.npr.org/2011/04/16/135415563/colin-stetson-horn-of-plenty; Accessed: 20 February 2016.

Quinlivan, Davina. 2012. The Place of Breath in Cinema. Edinburgh: Edinburgh University Press.

Rahaim, M. 2008. Gesture and Melody in Indian Vocal Music. Gesture 8(3): 325-347. 2012. Musicking Bodies: Gesture and Voice in Hindustani Music. Middletown, CT: Wesleyan University Press.

Sanden, P. 2013. Liveness in Modern Music: Musicians, Technology, and the Perception of Performance. London: Routledge.

Savage, S. 2011. Bytes and Backbeats: Repurposing Music in the Digital Age. Ann Arbor, MI: University of Michigan Press.

Schafer, R.M. 1977. The Soundscape: Our Sonic Environment and the Tuning of the World. Rochester, VT: Destiny Books.

Singh, A. 2011. SXSW Friday: Featuring James Blake, Odd Future, Esben \& the Witch, Jamie Woon, Mount Kimbie. http://www.stereogum.com/662791/sxswfriday-featuring-james-blake-odd-future-esben-the-witch-jamie-woon-mountkimbie/photo/attachment/sxsw-colin-stetson/; Accessed: 13 December 2016.

Small, C. 1998. Musicking: The Meanings of Performing and Listening. Middletown, CT: Wesleyan University Press.

Solomon, M. 1998. Beethoven. New York: Schirmer Books. Second Edition. First edition 1977.

Williams, D. 2014. Tracking Timbral Changes in Metal Productions from 1990 to 2013. Metal Music Studies 1(1): 39-68.

Zagorski-Thomas, $\mathrm{S}$. 
2007. The Musicology of Record Production. Twentieth-Century Music 4(2): 189-207.

2010. The Stadium in Your Bedroom: Functional Staging, Authenticity and the Audience-Led Aesthetic in Record Production. Popular Music 29(2): 251 266.

2014. The Musicology of Record Production. Cambridge: Cambridge University Press.

Zak, A.J. III. 2001. The Poetics of Rock: Cutting Tracks, Making Records. Berkeley: University of California Press.

\section{Discography}

Beatles, the. 1967. "Strawberry Fields Forever". Parlophone, 17 February, UK. Cher. 1998. "Believe". Warner Brothers, 19 October, USA.

Cyrus, Miley. 2013. "Wrecking Ball". Bangerz, RCA, 8 October, USA.

Guarneri Quartet. 1990. Beethoven: The Late String Quartets. RCA, 10 October, USA.

Stetson, Colin. 2013. New History Warfare, Vol. 3: To See More Light. Constellation, 30 April, USA.

Sia. 2015. "Alive". RCA, 25 September, USA.

\section{Videography}

Cyrus, M. 2013. Miley Cyrus LIVE Wrecking Ball at iHeartRadio 2013. https://www.youtube.com/watch?v=00pFIYORgLo; Accessed: 30 October 2016.

Cyrus, M. 2014. Miley Cyrus Cries During Wrecking Ball Live at Staples Center Bangerz Tour YouTube. https://www.youtube.com/watch?v=QajZotnDh7k; Accessed: 30 October 2016.

Stetson, C. 2011. Colin Stetson Breaks down "Judges". https://www.youtube.com/watch?v=UejNbSrJluA: Accessed: 21 February 2016.

Stetson, C. 2013 Colin Stetson - High Above a Grey Green Sea (Live in Boston). https://www.youtube.com/watch?v=UxECzyNNI74; Accessed: 13 December 2016.

Stetson, C. 2015 Colin Stetson Eaux Claires Festival, 7-18-2015. https://www.youtube.com/watch?v=izPj_ODS54l; Accessed: 13 December 2016.

\section{Concerts}

Stetson, C. 2014. Concert at Schubas Tavern, Chicago, IL, 22 April. 